\section{The Worldwide Emergence of Liberal Education}

\section{Kara A. Godwin}

Kara A. Godwin is a visiting scholar and consultant at the Center for International Higher Education at Boston College. E-mail: kara.godwin@gmail.com.

$\mathrm{D}$ uring the last two decades, liberal education-often called liberal arts or general education-has emerged with surprising prevalence in places like Russia, India, Ghana, China, Israel, the Netherlands, Chile, Bangladesh, and Brazil-places where it has rarely existed before. This is not an isolated phenomenon. It is a small, but potentially meaningful, global trend.

For centuries, higher education in most of the world has been organized around professional studies and a utilitarian philosophy. Its purpose has been to create a labor force capable of staffing needed positions in industry, health care, schools, and public services. Students, as a result, participate in curricula focused on their field of study to become attorneys, engineers, doctors, accountants, and teachers, etc.

Conversely, liberal education, despite its Greek roots, has long been considered a distinctly American tradition. It is commonly associated with US liberal arts colleges, though also widely available in some American research universities. Contemporary program developments and reforms in non-US contexts are a phenomenon for two reasons. The number and geographic evolution of programs in recent years is unexpected, and the philosophy of liberal education forms a sharp contrast to traditional postsecondary curriculum outside the United States.

Nonetheless, the global emergence of liberal education has taken place relatively unnoticed. With some surprising results, a new study provides an inaugural profile about where, when, and in what format liberal education is emerging worldwide. Based on analysis of the Global Liberal Education Inventory (GLEI), a new catalogue of 183 non-US liberal education programs, the study raises critical questions about liberal education's presence in new cultural milieus.

\section{A Brief Definition}

The definition of "liberal education," along with "liberal arts" and "general education," has been conflated and contested for centuries. Explained only briefly here, three criteria were used to qualify programs for inclusion in the GLEI. Contrary to the specialized, career-focused curriculum that has been the standard postsecondary norm in most of the world, liberal education is (I) interdisciplinary providing a broad knowledge base from social science, humanities, and natural/physical science; (2) includes a "general education" protocol, courses or curriculum required for all students in a program; and (3) emphasizes at least two of the following: transferable skills-written and oral communication, analysis and synthesis, problem solving, information and quantitative literacy, reasoning or logic, critical thinking, creativity, etc., citizenship/social responsibility/ethics, global competence, and/or student-centeredness and holistic student development.

"General education" can be a confusing term in an international context, where it is sometimes used in place of the more contentious "liberal education" descriptor. It is possible for a program to offer general education without being liberal. It is also possible for a program to be labeled "general education," when the curriculum actually includes all three elements of liberal education mentioned above, and qualifies it for inclusion in the GLEI. Hong Kong is a primary example.

\section{Where Has Liberal Education Emerged Globally?}

Liberal education now exists in at least 58 countries and on every continent with postsecondary institutions, a declaration that could not be made just a few decades ago. Surprisingly, Asia-not Europe-has a stronger presence of liberal education than any region beyond North America. Based on the GLEI, Asia accounts for 37 percent of liberal education programs outside the United States. Three-fourths of the Asian liberal education programs are in China, India,

\section{Conversely, liberal education, despite its Greek roots, has long been considered a distinctly American tradition.}

and Japan, while only a few but important initiatives are in lesser developed Bhutan, Afghanistan, and Bangladesh. Central government interest in improving critical thinking and creativity in China is driving liberal education reform that contrasts the country's traditional curriculum. Also in the region, an unprecedented system-wide mandate for liberal education is taking place throughout Hong Kong's public higher education system. General and liberal education initiatives, along with changes to the degree cycles, are being implemented at all public institutions.

In Europe, which accounts for 32 percent of programs outside the United States, liberal education can be loosely 
distinguished between developments in the western and eastern subregions. In the west, liberal education reforms are often affiliated with the Bologna process and the need to better define content of first-degree undergraduate education. New programs like those in the Netherlands, for example, were created to diversify higher education and encourage an echelon of excellence in an otherwise egalitarian system. Conversely, liberal education is more closely related to shifts in political power and post-Cold War emerging democracies in eastern states where experiments with new educational philosophies are gaining acceptance.

In the Middle-East and Arab countries, liberal education is commonly called "American-style" education and, from the public's point of view, often synonymous with quality. Its market success as a naming convention, however, does not reflect the frequent cultural challenges posed by gender segregation and the prominence of religious law. The region only accounts for 9 percent of GLEI initiatives, but it attracts much attention as an unusual destination for education that encourages critical thinking.

Based on the GLEI, liberal education is comparably less prevalent in Latin America (7 programs or $4 \%$ of those outside the United States), Africa (4 programs or $2 \%$ ), and Oceania (7 programs or 4\%). Latin America's liberal education initiatives are often affiliated with the Catholic Church and unlike many of the inventory's programs, none of them use English as their language of instruction. African programs while small in number, offer unique postsecondary opportunities, where higher education is strained by demand and where founders hope the philosophy will impact economic and social development in Kenya, Morocco, Ghana, and Nigeria. In Oceania, Australia is the only country with liberal education initiatives. Unlike most regions where liberal education plays a less than prominent role across higher education systems, the top-ranked University of Melbourne has developed a liberal undergraduate curriculum now adopted by other world-class institutions.

Finally, because the United States was excluded from this study, Canada was the only representative from the North American region. Canada has 2I programs, more than any other single country. On the whole, however, it seems to have little influence on the dialogue and activity around recent global liberal education developments. Canada has a longer history of liberal education than most countries; only 3 initiatives have emerged since I990. Two of these, the $\mathrm{U}_{4}$ League, a consortium of four long-standing liberal education institutions, and Quest University, which delivers a unique curriculum in a diverse academic culture, have potential to set new precedents for liberal education in Canada and liberal education more broadly.

\section{When and How Has Liberal Education Emerged Glob-} ALLY?

Analysis of the GLEI illustrates that the chronological evolution of liberal education worldwide is striking. While traces of the education philosophy have existed at universities since the founding of Oxford and Cambridge, 59 percent of the I83 GLEI programs began since I990. A remarkable 44 percent of all liberal education programs outside the United States were founded since 2000 .

Globally, liberal education programs are divided almost evenly between public and private initiatives, although significant differences exist in the number of public/private programs when analyzed by region. Given the rapid growth of private education, it is surprising that since 2000 there have been 20 percent more public liberal education programs than private-due in some part to initiatives in China and Hong Kong.

\section{The global emergence of liberal educa- tion has taken place relatively unno- ticed.}

English is used by 8I percent of the programs globally and by 46 percent of the programs in countries where it is not an official language. Although many programs have institutional affiliations or formal partnerships, 57 percent of liberal education programs operate independently. Of those with an affiliation, the number of domestic partnerships (between two programs in the same country) exceeds cross-border relationships. Unexpectedly, only one-third of all liberal education institutional affiliations are with programs in the United States.

\section{Liberal Education Worldwide: Percolating not Profliferating}

Increasing interest in liberal education globally is not merely a coincidence; it is a trend but one whose significance remains difficult to discern at this time. With few exceptions-like Hong Kong University of Science and Technology and Melbourne University in Australia-liberal education's development remains a phenomenon occurring on the periphery without a great deal of influence on-mainstream, world-class education where attention, resources, and research knowledge are concentrated.

The number of programs and the number of students enrolled in liberal education are minute compared to more traditional, professional postsecondary degrees. Only 2 per- 
cent of countries (5 total including the United States) have more than Io liberal education programs. The vast majority of GLEI countries, nearly 80 percent, have just one to three initiatives in their higher education systems. "Crowding at the bottom" of the global distribution dilutes the potential for liberal education to influence its own perceived legitimacy or the mainstream postsecondary sector more generally.

This is an observation, however, not a prescription for developing more liberal education programs. The GLEI study ignited several questions that challenge the positive assumptions often proclaimed by liberal arts enthusiasts. Included among them are the difficulties of designing culturally relevant curricula; required shifts in approaches to learning and teaching; lack of affordability and access to liberal education that perpetuates elitism and inequity; and issues of neoliberalism and cultural hegemony that might result from western influence on education in other parts of the world.

\section{Financing of Education Hubs: Who Are the Investors?}

\section{JANE KNIGHT}

Jane Knight is adjunct professor at the Ontario Institute for Studies in Education, University of Toronto, Canada. E-mail: janeknight@sympatico.ca.

I nternational education hubs are the latest development in the international higher education landscape. A countrylevel education hub is a planned effort to build a critical mass of local and international actors-higher education institutions and providers, students, research and development centers, and knowledge industries-who work collaboratively on education, training, and knowledge production/innovation. To date, six countries-Qatar, United Arab Emirates, Singapore, Malaysia, Hong Kong, and Botswana-claim to be education hubs. But how are they financed? Are the investors public or private? Are they local or foreign based? Are the current-funding models sustainable? These are important questions worthy of closer examination.

\section{QATAR}

Each country has its own capacity and strategies to fund education hub initiatives. Qatar is an interesting but unique model. All physical infrastructure and facilities are provid- ed for foreign-branch campuses and companies located in Education City and the Science and Technology Park. Furthermore, Ioo percent of the sizable operating costs for the Io branch campuses and the new graduate-level university, Hammid bin Khalifa University, are covered by the Qatar Foundation. The annual operating costs to support Education City, Science and Technology Park and the extensive array of research programs and grants is the responsibility of the Qatar government and is extremely high. Is this government supported full funding model sustainable and is it optimal? In essence, Qatar is importing and purchasing the majority of education programs, services, and research for the education hub activities. A pivotal question is how long should a country attempt to build and strengthen domestic capacity by purchasing and importing foreign expertise. It has been I7 years since Qatar first started its work on inviting select foreign universities to establish specific programs in Education City. Is this the first phase of Qatar's long-term plan to develop more domestic human resource capacity as it loosens its reliance on natural gas and foreign expatriate talent, or is this becoming modus operandi? If so, is it a sustainable and effective model? If not, what will be the second phase?

\section{International education hubs are the latest development in the international higher education landscape.}

\section{United Arab Emirates}

The United Arab Emirates (UAE) offers a completely different set of circumstances in terms of funding, investments, and revenue generation. Each emirate has developed its own approach to making UAE an education hub. Abu Dhabi has invited world renowned institutions, such as New York University and the Sorbonne, to set up branch campuses in customized facilities provided by Abu Dhabi Government. In addition, the Massachusetts Institute of Technology was invited to help develop and advise on the development of Masdar Institute of Technology and Masdar City, the first carbon free zone in the world. Masdar City hosts world-class research facilities, scientists, and graduate programs-all of which are supported by the Abu Dhabi government. This represents an enormous domestic public investment.

Dubai is a different story. Dubai's Strategic Plan called for the establishment of several theme-based economic free zones. Two of these are education focused-Knowledge 